\title{
Functional evaluation before and after laryngo-tracheal resection
}

\author{
Nina Rahimi ${ }^{1}$, Imme Roesner ${ }^{2}$, Thomas Schweiger ${ }^{1}$, Matthias Evermann ${ }^{1}$, Doris-Maria Denk-Linnert ${ }^{2}$, \\ Walter Klepetko ${ }^{1}$, Konrad Hoetzenecker ${ }^{1}$
}

${ }^{1}$ Department of Surgery, Division of Thoracic Surgery, ${ }^{2}$ Department of Otolaryngology, Division of Phoniatrics and Speech Language Therapy, Medical University of Vienna, Vienna, Austria

Contributions: (I) Conception and design: K Hoetzenecker, DM Denk-Linner; (II) Administrative support: W Klepetko; (III) Provision of study materials or patients: DM Denk-Linnert, W Klepetko; (IV) Collection and assembly of data: N Rahimi, I Roesner, T Schweiger; (V) Data analysis and interpretation: N Rahimi, T Schweiger, M Evermann; (VI) Manuscript writing: All authors; (VII) Final approval of manuscript: All authors. Correspondence to: Konrad Hoetzenecker, MD, PhD. Division of Thoracic Surgery, Medical University of Vienna, Waehringer Guertel 18-20, A-1090 Vienna, Austria. Email: konrad.hoetzenecker@meduniwien.ac.at.

\begin{abstract}
Laryngotracheal resections have become a clinical routine in experienced airway centers and even extended glotto-subglottic resections and reconstructions can be performed with low complication rates and excellent long-term airway patency. However, reports on the functional outcome after laryngotracheal resections are sparse and there is no general agreement among airway surgeons, which functional evaluations should be performed before and after surgery. The following review provides an overview on basic assessment tools, which can be used to objectively report functional outcome after laryngotracheal surgery.
\end{abstract}

Keywords: Laryngotracheal resection; functional evaluation; swallowing; voice

Submitted Jan 31, 2020. Accepted for publication Feb 17, 2020.

doi: $10.21037 /$ tcr.2020.02.53

View this article at: http://dx.doi.org/10.21037/tcr.2020.02.53

\section{Background}

Laryngotracheal stenosis (LTS) is a rare condition that can be caused by various benign and malignant diseases. The abnormal narrowing of the upper airway leads to severe dyspnea and treatment is inevitable $(1,2)$. The etiology of LTS can be grouped into acquired and congenital causes. In adults LTS is mostly acquired and can result from previous intubation or tracheostomy, systemic disease, trauma, infection, or idiopathic reasons. Congenital causes mostly affect children and include laryngeal atresia, laryngeal webs, and complete or absent tracheal rings $(3,4)$.

The therapeutic strategy for subglottic stenosis is dependent on the disease itself and patient-bound parameters. Regardless of the nature of the underlying disorder, the treatment of LTS requires a high level of expertise, careful diagnosis and an experienced surgical team that can handle extended operative techniques (5). The Laryngotracheal Team Vienna was founded in 2010 with the purpose of concentrating these rare operations within a dedicated team. The core team is formed by three thoracic surgeons, three phoniatricians and a dedicated anesthetist. Pediatric pulmonologists, pediatric surgeons and pediatric cardiac surgeons augment the expertise for selected cases. Besides a structured documentation, a complete morphological and functional assessment of the larynx including voice and swallowing function is performed in every patient before and after the operation. Pre- and postoperative lung function tests, indirect videolaryngo(strobo) scopy, as well as analyses of swallowing [flexible endoscopic evaluation of swallowing (FEES)] and voice and are performed and prospectively documented (Table 1).

Contemporary laryngotracheal surgery can provide a complete and long-term restoration of the airway. In the vast majority of patients, lung function parameters return to normal and breathing related symptoms are revealed. Unlike endoscopic procedures, surgery leads to excellent long-term results. Recent work from the Boston Airway Group and data from the North American Collaboration of Airway Surgeons report a surgical recurrence rate of $12-28 \%$ for endoscopic laser resections or dilatation, but only $1 \%$ for surgical treatments $(2,6,7)$. One of the main 
arguments used against primary surgery is that voice and swallowing are impaired to a higher degree compared to endoscopic procedures. This view is not supported by evidence. In experienced hands, laryngotracheal surgery can be performed with only a minimal impact on glottic functions. We and others have shown that the best results can be obtained in patients primarily referred to surgery $(8,9)$. Pre-treated patients usually require more extended surgical techniques and functional outcomes are worse than in previously untreated patients $(6,7)$.

\section{Tools of functional assessment of the glottis}

\section{Transnasal videolaryngo(strobo)scopy}

Transnasal videoendoscopy of the larynx, preferably using chip-on the tip endoscopes, combined with a video documentation is an indispensable part of preand postoperative functional assessment (Figure 1). In a completely awake patient, supra-, intra- and high infraglottic morphological and functional abnormalities can be visualized. Chip-on the tip transnasal videoendoscopy is the current gold standard to assess respiratory vocal fold mobility. Additional stroboscopy helps to evaluate the glottic closure /incompetence and the muscle tone. In experienced hands, the information obtained goes far beyond a mere documentation of a vocal fold paralysis. A selection of abnormalities is described below:

\section{Impaired abduction of the vocal fold}

Unlike vocal fold paralysis, vocal fold abduction is preserved but reduced. Unilateral impaired abduction can be the result of a scar band, partially fixating the vocal fold-a situation frequently found after a failed attempt of laser enlargement of a subglottic stenosis.

\section{Arytenoid tilting}

When lateral parts of the cricoid are resected too liberally or in cases of extensive mobilization of the larynx, the anchoring of the arytenoids by surrounding soft tissue can be weakened. This can result in an inspiratory protrusion of the arytenoids into the airway.

\section{Arytenoid fixation or ankylosis of the cricoarytenoid joint}

Ankylosis results in a fixation of the joint mostly due to a scar in the posterior aspect of the glottis or after long-termintubation.
Table 1 Functional assessment before and after laryngotracheal resections

Transnasal videolaryngo(strobo)scopy

Flexible endoscopic evaluation of swallowing (FEES)

Voice assessment (perceptual voice sound scaling, voice range profile, Goettingen hoarseness diagram)

Voice Handicap Index (VHI)

Dysphagia Handicap Index (DHI)

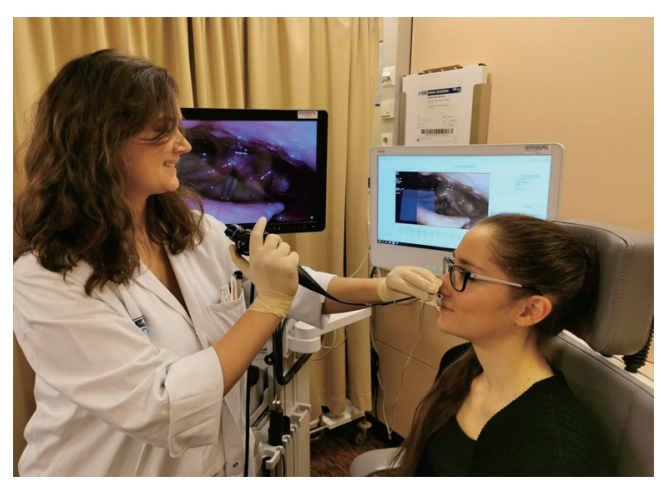

Figure 1 Shows a typical setting of a transnasal videolaryngoscopy with a chip-on the tip endoscope. The digital recording helps to facilitate diagnosis and to document findings.

\section{Vocal fold edema}

Swelling of the glottic area is something frequently encountered after high cricotracheal resections or intralaryngeal reconstructions. A significant swelling with temporal stridor is observed in $30-40 \%$ of laryngotracheal resections/reconstructions. Transnasal laryngoscopy should be liberally used to monitor the extent of swelling and guide therapy (Videos 1,2).

\section{Fiber-optic/FEES}

A FEES should be routinely performed before and after repair of a LTS (Figure 2). A preoperative swallowing assessment is essential to assess the risk for postoperative impairment of swallowing and thus determine the optimal mode of postoperative nutritional delivery. A FEES consists of a flexible (video) laryngoscope in combination with an evaluation of the patient's swallowing mechanism. Dyed food (e.g., dyed saliva, pudding, yogurt, crackers) in different consistencies are sequentially given to the patient. The pharynx and larynx are viewed, and the 


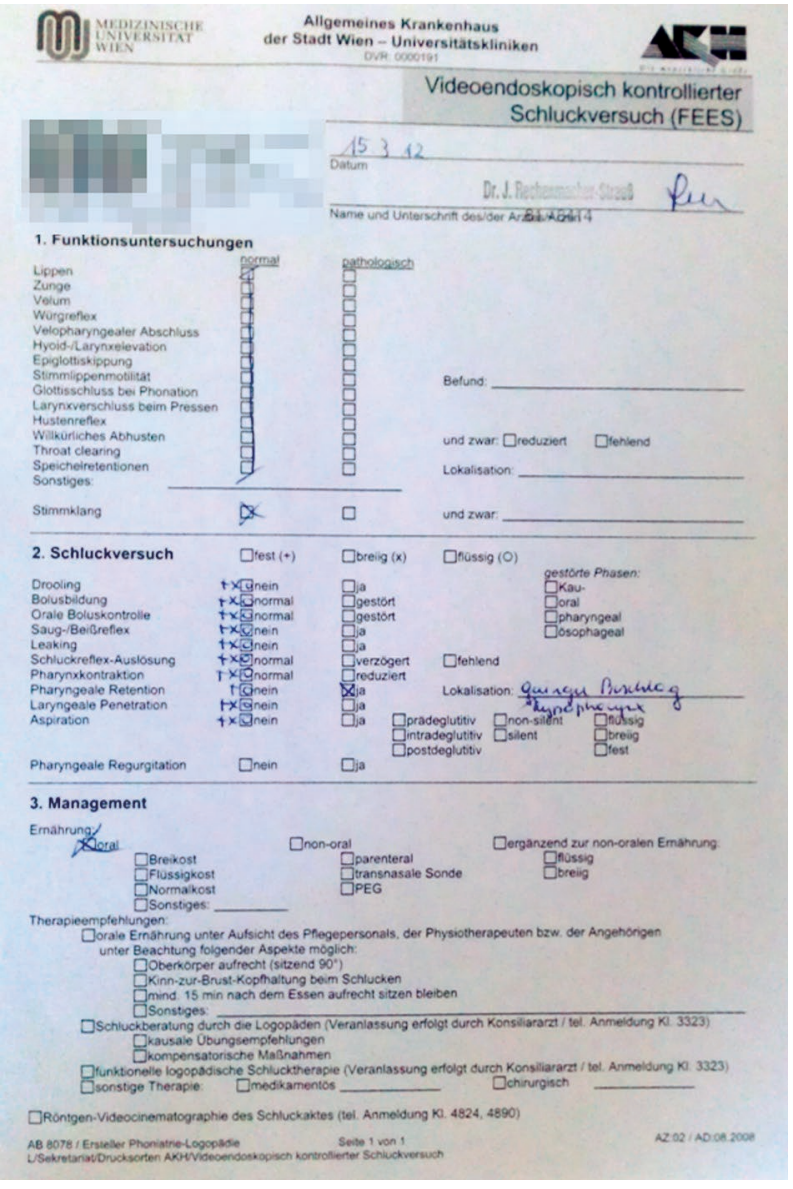

Figure 2 A flexible endoscopic evaluation of swallowing (FEES) allows a detailed examination and documentation of swallowing. The report is made according to the Langmore Protocol.

safety of swallowing is determined. Besides documenting the patient's ability to swallow different consistencies, laryngoscopy provides physicians with information pertaining to the mobility of vocal folds (10). A structured FEES should include a separate reporting of pooling (retentions of food in the mouth or pharynx), penetration (food or liquids go into the airway as far as the glottic level), or aspiration (food or liquids can be found below the vocal folds). The information if aspiration or penetration results in an adequate coughing reflex is especially important. A preoperative FEES assessment mainly serves to obtain the baseline and to screen for preexisting abnormalities. During the early postoperative course FEES can be used as a guide to decide on the start of oral intake.

Resections and reconstructions of the laryngotracheal border zone can directly impact swallowing function.
Swallowing is a complex interplay of a variety of nerval and muscular structures. Unlike general beliefs, postoperative swallowing impairment is not solely dependent on the vocal fold function. Equally important are a preserved laryngeal elevation as well as tilting of the epiglottis. For standard cricotracheal resections, postoperative swallowing impairment is rare but the incidence of transient disorders increases when the resection reaches up to the level of the vocal folds. Laryngotracheal reconstructions with rib cartilage interpositions represent the highest risk of postoperative penetration/aspiration. Therefore, oral intake should be paused in the early postoperative phase and FEES should be used to decide when to start oral feeding.

\section{Subjective voice assessment}

Voice assessment is measured by perceptive evaluation of voice quality and acoustic analyses. The so-called RHB scale defines roughness, breathiness and the overall grade of dysphonia (hoarseness) as judged by the listener on a scale of 0 to 3 (0: normal, 1: mild, 2: moderate, 3: severe).

\section{Objective voice assessment}

A complete workup of voice includes recording of the speaking and the singing voice. Software supported quantification of voice parameters can be recorded including phonation time, shimmer and jitter by using the DiVAS voice diagnostic tool (XION medical, Berlin, Germany). The Goettingen hoarseness diagram represents an evolution of the quite basal RHB score towards a semi-quantitative documentation system of voice quality. It describes the periodicity (roughness) and the noise content (breathiness) of voices (Figure 3). The voice range profile (minimum and maximum intensity levels across the vocal range) is usually determined before and three months after an operation involving the laryngotracheal border zone (Figure 4).

\section{Questionnaire/patient-based assessment-Voice Handicap Index (VHI) and Dysphagia Handicap Index (DHI)}

Patient based questionnaires are increasingly used to determine voice quality and swallowing function. The VHI (11) contains 30 questions concerning voice limitation. The items are divided into 3 areas: functional, physical and emotional aspects of voice disorder. Each of the 30 


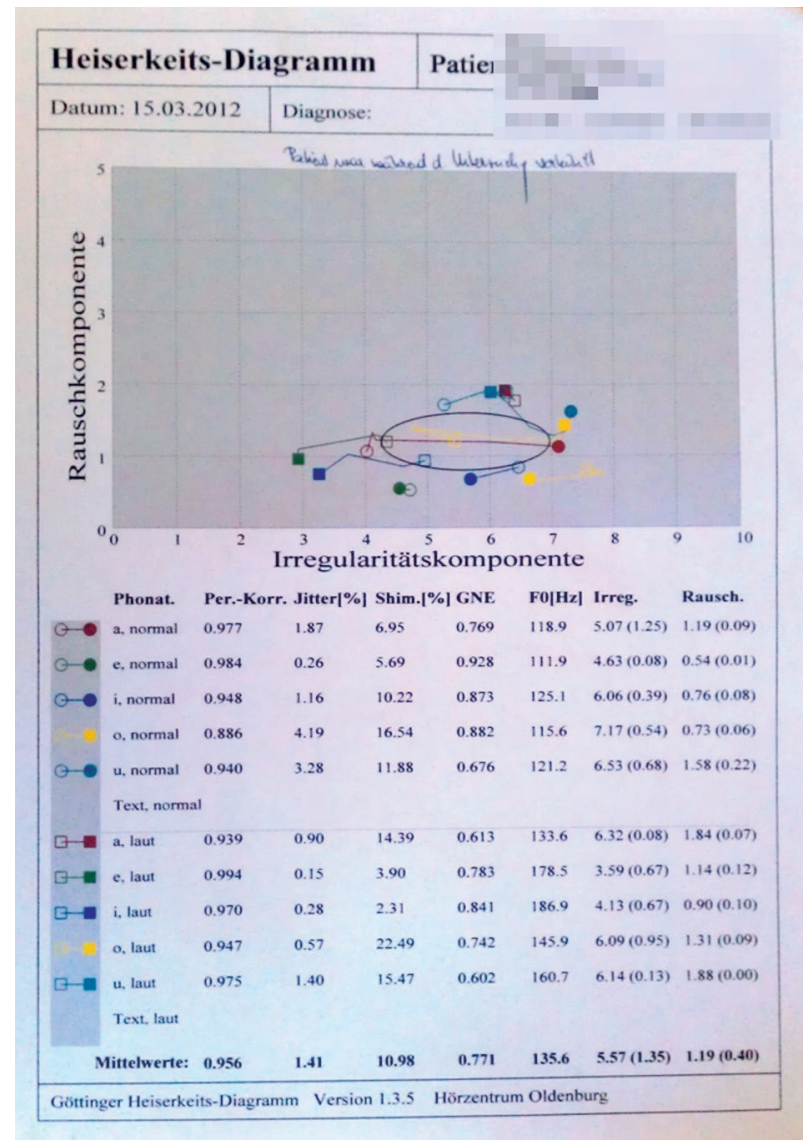

Figure 3 The Goettingen hoarseness diagram is a tool to objectively quality of voice.

items is evaluated by the patient on a scale from 0 to 4 . Gradations between never [0], rare [1], sometimes [2], often [3] and always [4] are possible. A score of 120 represent the maximum disability that can be recorded.

The DHI (12) is a 25-item questionnaire assessing the physical, functional, and emotional aspects of dysphagia and the effect on patients' quality of life. The DHI provides a broad picture of the health of an individual and can assist physicians in the decision-making process of care. The goal is to provide an efficient and clinically relevant patientreported outcome tool for dysphagia.

\section{Surgical techniques and functional outcomes}

Literature on functional outcome after laryngotracheal surgery is sparse. Published evidence is limited to a handful of publications, mainly looking at standard cricotracheal resection (Grillo technique). Little is known about the impact of extended procedures such as posterior mucosectomy, lateral cricoplasty, anterior laryngeal splits or laryngotracheal reconstructions with dorsal rib cartilage enlargements grafts. Available evidence is summarized below:

\section{Cricotracheal resection (Grillo technique)}

This standard procedure was first described by Grillo in 1982 (13) has achieved excellent functional results for the treatment of subglottic stenosis (14-16). The technique was adopted by most airway groups, many of which have meanwhile reported large series of patients with high operative success rates and low complication rates (17-22). The Grillo technique led to excellent long-term results in patients with an anterior or circular type of stenosis. Interestingly, the preservation of the Musculus cricothyroideus seems to be important and might lead to a better voice function postoperatively $(1,23)$.

\section{Extended cricotracheal resection (including posterior mucosectomy and lateral cricoplasty)}

The standard technique of cricotracheal resection does not consider lateral narrowing in the subglottic space. A modification of the standard Grillo technique was described by Liberman and colleagues (24). The "tailored cricoplasty" allows increased postresectional luminal diameter of the subglottic airway. Early- and midterm outcome in the initial report by Liberman were favorable. None of the 18 patients required reoperation, tracheostomy or readmission during the follow-up period. To date, there is no literature on functional outcome, but there is evidence that the extent of the height is crucial for postoperative results: the higher and closer the vocal fold to the resection is, the greater is the impact on voice. A different approach to increase the subglottic diameter has been proposed by Ciccone et al. (25). After resection of the anterior portion of the cricoid ring and cricothyroid membrane, a longitudinal incision on the midline with an extent of $2 \mathrm{~cm}$ (partial laryngofissure) is performed. This technique proved to be sufficient obtaining an optimal caliber and permanent enlargement of the subglottic space with only one anastomotic suture.

\section{Laryngotracheal reconstruction}

The Couraud technique combines a subglottic resection 

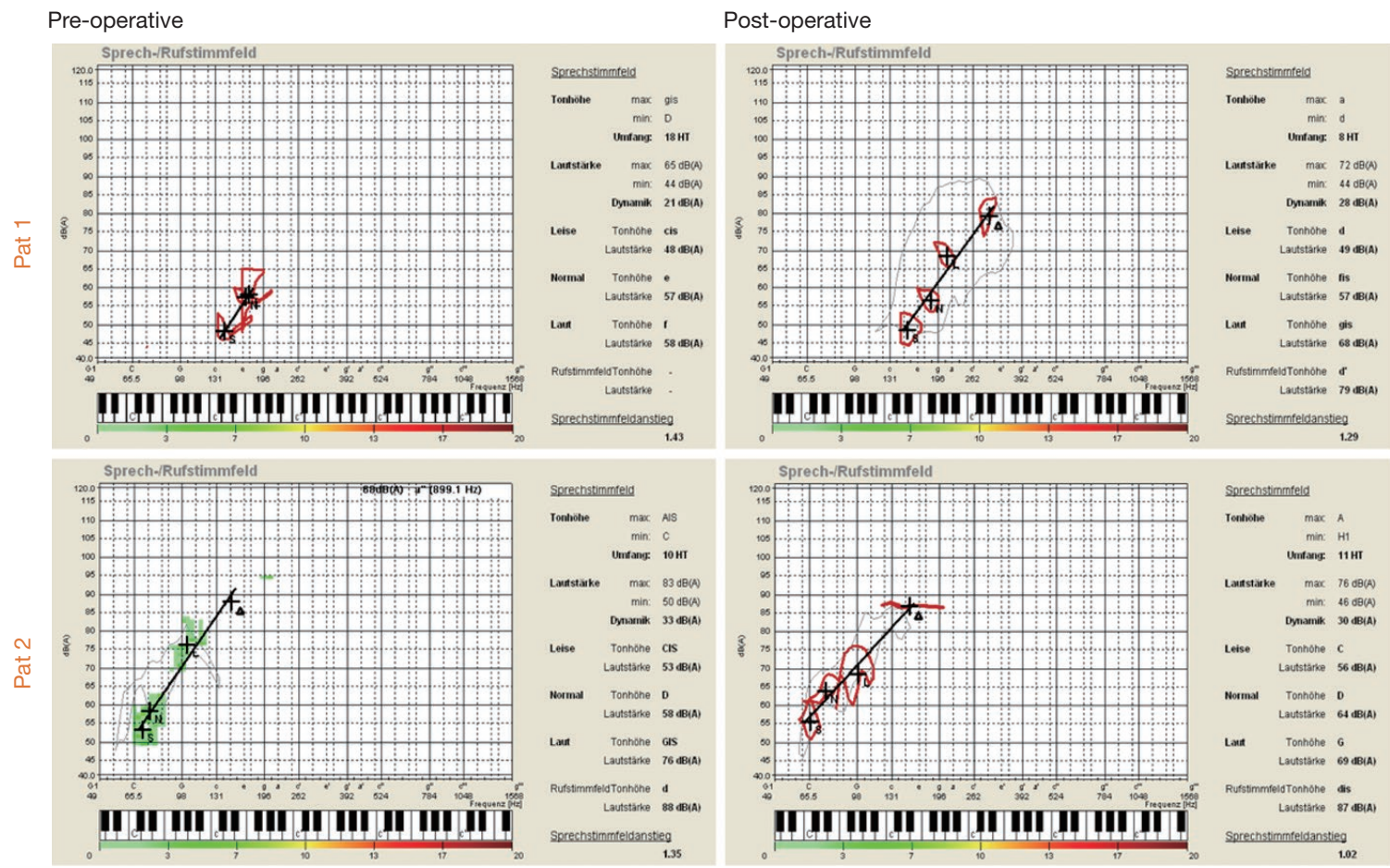

Figure 4 Pre- and postoperative voice range profiles: quantitative voice assessment using computer based evaluation tools. These two patients received a single-stage laryngotracheal reconstruction with a posterior rib cartilage graft.

with an enlargement of the glottis (26). Couraud and colleagues developed this reconstructive procedure in the 1980s and used the technique in twelve well selected patients. One of the patients died but the remaining 11 were reported to have good functional results and acceptable quality of voice (27). Additional information was reported by Morcillo and colleagues (28): a group of 20 patients underwent laryngotracheal reconstructive surgery between 1986 and 2011. There was one patient with temporary swallowing disorders postoperatively, and 4 patients required reoperation for restenosis or larynx inconsistency. Although satisfactory outcomes, the technique carries the disadvantage of postoperative stenting. A modification of Couraud's technique was developed by the Vienna Laryngotracheal Team (8). Despite the complexity of such a reconstruction the functional outcome was excellent in all of the five initially reported cases. Anastomotic healing was good, postoperative lung function parameters were improved, and voice quality was found to be excellent to satisfactory. Only a mild impairment in the measured hoarseness parameters was found. Current literature from Lausanne, Switzerland by Monnier (29) suggests good functional results using a similar technique in children.

\section{Conclusions}

Overall, few studies describe the functional outcome of patients after cricotracheal resections. The surgical procedure almost leads to a cure but is always in competition with endoscopic procedures. For this reason, it is essential to accurately assess the functional outcome of surgical interventions. We have evaluated patients receiving laryngotracheal interventions pre- and postoperatively for 10 years. Our standard protocol measures voice, lung function and swallowing function using the techniques and tools described above. An optimal treatment, however, always requires a multidisciplinary assessment of the patient's individual situation by thoracic surgeons, phoniatricians, speech language pathologists, ENT surgeons, pulmonologists and anesthesiologists.

\section{Acknowledgments}

Funding: None. 


\section{Footnote}

Provenance and Peer Review: This article was commissioned by the editorial office, Translational Cancer Research for the series "Recent Developments in Benign Tracheal Stenosis". The article has undergone external peer review.

Conflicts of Interest: All authors have completed the ICMJE uniform disclosure form (available at http:// dx.doi.org/10.21037/tcr.2020.02.53). The series "Recent Developments in Benign Tracheal Stenosis" was commissioned by the editorial office without any funding or sponsorship. KH served as the unpaid Guest Editor of the series. The authors have no other conflicts of interest to declare.

Ethical Statement: The authors are accountable for all aspects of the work in ensuring that questions related to the accuracy or integrity of any part of the work are appropriately investigated and resolved.

Open Access Statement: This is an Open Access article distributed in accordance with the Creative Commons Attribution-NonCommercial-NoDerivs 4.0 International License (CC BY-NC-ND 4.0), which permits the noncommercial replication and distribution of the article with the strict proviso that no changes or edits are made and the original work is properly cited (including links to both the formal publication through the relevant DOI and the license). See: https://creativecommons.org/licenses/by-nc-nd/4.0/.

\section{References}

1. Timman ST, Schoemaker C, Li WWL, et al. Functional outcome after (laryngo)tracheal resection and reconstruction for acquired benign (laryngo)tracheal stenosis. Ann Cardiothorac Surg 2018;7:227-36.

2. Gelbard A, Anderson C, Berry LD, et al. Comparative Treatment Outcomes for Patients With Idiopathic Subglottic Stenosis. JAMA Otolaryngol Head Neck Surg 2019:1-10.

3. Lorenz RR. Adult laryngotracheal stenosis: etiology and surgical management. Curr Opin Otolaryngol Head Neck Surg 2003;11:467-72.

4. Lewis S, Earley M, Rosenfeld R, et al. Systematic review for surgical treatment of adult and adolescent laryngotracheal stenosis. Laryngoscope 2017;127:191-8.

5. Volmerig J, Hecker E. Tracheal Surgery. Zentralbl Chir
2017;142:320-9.

6. Tapias LF, Mathisen DJ. Prevention and management of complications following tracheal resections-lessons learned at the Massachusetts General Hospital. Ann Cardiothorac Surg 2018;7:237-43.

7. Wang H, Wright CD, Wain JC, et al. Idiopathic Subglottic Stenosis: Factors Affecting Outcome After Single-Stage Repair. Ann Thorac Surg 2015;100:1804-11.

8. Hoetzenecker K, Schweiger T, Roesner I, et al. A modified technique of laryngotracheal reconstruction without the need for prolonged postoperative stenting. J Thorac Cardiovasc Surg 2016;152:1008-17.

9. Hoetzenecker K, Schweiger T, Schwarz S, et al. Summarized institutional experience of paediatric airway surgerydagger. Eur J Cardiothorac Surg 2016;49:1119-26.

10. Smith MM, Cotton RT. Diagnosis and management of laryngotracheal stenosis. Expert Rev Respir Med 2018;12:709-17.

11. Jacobson BH, Johnson A, Grywalski C, et al. The Voice Handicap Index (VHI): Development and Validation. Am J Speech Lang Pathol 1997;6:66-70.

12. Silbergleit AK, Schultz L, Jacobson BH, et al. The Dysphagia handicap index: development and validation. Dysphagia 2012;27:46-52.

13. Grillo HC. Primary reconstruction of airway after resection of subglottic laryngeal and upper tracheal stenosis. Ann Thorac Surg 1982;33:3-18.

14. Grillo HC, Mark EJ, Mathisen DJ, et al. Idiopathic laryngotracheal stenosis and its management. Ann Thorac Surg 1993;56:80-7.

15. Ashiku SK, Kuzucu A, Grillo HC, et al. Idiopathic laryngotracheal stenosis: effective definitive treatment with laryngotracheal resection. J Thorac Cardiovasc Surg 2004;127:99-107.

16. Grillo HC, Mathisen DJ, Wain JC. Laryngotracheal resection and reconstruction for subglottic stenosis. Ann Thorac Surg 1992;53:54-63.

17. El-Fattah AM, Kamal E, Amer HE, et al. Cervical tracheal resection with cricotracheal anastomosis: experience in adults with grade III-IV tracheal stenosis. J Laryngol Otol 2011;125:614-9.

18. Piazza C, Del Bon F, Paderno A, et al. Complications after tracheal and cricotracheal resection and anastomosis for inflammatory and neoplastic stenoses. Ann Otol Rhinol Laryngol 2014;123:798-804.

19. Yamamoto K, Jaquet $Y$, Ikonomidis C, et al. Partial cricotracheal resection for paediatric subglottic stenosis: 
update of the Lausanne experience with 129 cases. Eur J Cardiothorac Surg 2015;47:876-82.

20. White DR, Cotton RT, Bean JA, et al. Pediatric cricotracheal resection: surgical outcomes and risk factor analysis. Arch Otolaryngol Head Neck Surg 2005;131:896-9.

21. Auchincloss HG, Wright CD. Complications after tracheal resection and reconstruction: prevention and treatment. J Thorac Dis 2016;8:S160-7.

22. Maddaus MA, Toth JL, Gullane PJ, et al. Subglottic tracheal resection and synchronous laryngeal reconstruction. J Thorac Cardiovasc Surg 1992;104:1443-50.

23. Timman ST, Siddiqi S, Verhagen A. The Tribulation of Tracheal Surgery. Ann Thorac Surg 2019;108:1586.

24. Liberman M, Mathisen DJ. Tailored cricoplasty: an improved modification for reconstruction in subglottic tracheal stenosis. J Thorac Cardiovasc Surg 2009;137:5738; discussion 578-9.

Cite this article as: Rahimi N, Roesner I, Schweiger T, Evermann M, Denk-Linnert DM, Klepetko W, Hoetzenecker K. Functional evaluation before and after laryngo-tracheal resection. Transl Cancer Res 2020;9(3):2142-2148. doi: $10.21037 /$ tcr.2020.02.53
25. Ciccone AM, Vanni C, Maurizi G, et al. A Novel Technique for Laryngotracheal Reconstruction for Idiopathic Subglottic Stenosis. Ann Thorac Surg 2016;102:e469-71.

26. Couraud L, Hafez A, Velly JF, et al. Current reconstructive management of subglottic stenosis of the larynx with reference to sixty consecutively treated cases. Thorac Cardiovasc Surg 1985;33:263-7.

27. Couraud L, Jougon JB, Velly JF. Surgical treatment of nontumoral stenoses of the upper airway. Ann Thorac Surg 1995;60:250-9; discussion 259-60.

28. Morcillo A, Wins R, Gomez-Caro A, et al. Single-staged laryngotracheal reconstruction for idiopathic tracheal stenosis. Ann Thorac Surg 2013;95:433-9; discussion 439.

29. Monnier P. Partial Cricotracheal Resection and Extended Cricotracheal Resection for Pediatric Laryngotracheal Stenosis. Thorac Surg Clin 2018;28:177-87. 